\section{Radiotherapy for ocular tumours}

C Stannard 1 , W Sauerwein², G Maree ${ }^{3}$ and K Lecuona ${ }^{4}$

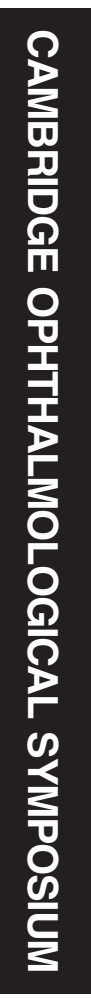

${ }^{1}$ Department of Radiation Oncology, Groote Schuur Hospital and University of Cape Town, Cape Town, South Africa

These have advanced significantly over the past decades so that the current range of therapeutic options can be confusing to non-specialists.

In this review we describe ionising radiation, how this is delivered to the eye and how different ocular tumours are irradiated.

\section{Ionising radiation}

Ionising radiation can be classified as electromagnetic or particulate.

\section{Electromagnetic radiation}

Electromagnetic radiation includes $\mathrm{X}$-rays and $\gamma$-rays. These are physically identical in nature and properties but differ in the way they are produced.

X-rays are produced in an electrical device that accelerates electrons to high energy, directing them on to a target such as tungsten. Part of the kinetic energy of the electrons is converted into $\mathrm{X}$-rays. ${ }^{1} \mathrm{Low}$-energy $\mathrm{X}$-rays, $100-250 \mathrm{kV}$, are produced in an X-ray tube. High energy $\mathrm{X}$-rays, $4-18 \mathrm{MV}$, are produced by a linear accelerator (linac).
${ }^{2}$ Department of Strahlenklinik, Universitstsklinikum Essen, Universitat Duisberg-Essen, Essen, Germany

${ }^{3}$ Department of Medical Physics, Groote Schuur Hospital and University of Cape Town, Cape Town, South Africa

${ }^{4}$ Department of Ophthalmology, Groote Schuur Hospital and University of Cape Town, Cape Town, South Africa

Correspondence:

C Stannard, Division of Radiation Oncology, Department

of Radiation Medicine, Groote

Schuur Hospital, Observatory,

Cape Town, Western Cape 7925

South Africa

Tel: + 2721404 4271;

Fax: + 27214045259

E-mail: Clare.Stannard@uct.ac.za

Received: 5 October 2012 Accepted: 8 October 2012 Published online: 23 November 2012

This paper was presented at the Cambridge Ophthalmology Symposium 13-14 September 2012
Keywords: radiotherapy; ocular tumours; brachytherapy; iodine-125; proton therapy 
$\gamma$-rays are emitted by radioactive isotopes as the unstable nucleus breaks up and decays in an attempt to reach a stable form. Isotopes used in ophthalmology include cobalt-60 (Co-60), iridium-192 (Ir-192), and iodine-125 (I-125).

\section{Particulate radiation}

Particulate radiations occur in nature and include electrons, protons, neutrons, $\alpha$-particles, negative $\pi$ mesons, and heavy charged ions.

High-energy electrons are accelerated in a linear accelerator and emerge without impinging on a target. They are less penetrating than X-rays because of their low mass.

$\beta$-rays are physically identical to electrons but are emitted from radioactive isotopes as they decay, for example, Strontium-90 (Sr-90), ruthenium-106 (Ru-106).

Therapeutic protons are produced by accelerating protons in a cyclotron.

\section{Radiation techniques}

RT is described according to whether the source of radiation is far (tele) or near (brachy) the target tissue.

\section{Teletherapy}

Teletherapy, otherwise known as external beam RT (EBRT), includes X-rays, Co-60 $\gamma$-rays, and electrons. Increasingly sophisticated methods of delivering RT have been developed to reduce the dose to surrounding normal tissues while maintaining a tumouricidal dose to the tumour. These include: (a) single or multiple collimated (shaped) fields; (b) three-dimensional conformal RT (computerised tomograhic planning, each field individually shaped); (c) intensity modulated RT (multiple fields, static or dynamic gantry, inverse planning to treat the target volume to full dose while restricting the dose to sensitive structures, and variation in intensity within each beam with a multileaf collimator to achieve this); and (d) stereotactic RT (multiple shaped beams or arcs all concentrating on the target volume). The patient must be immobilised to allow accurate delineation of the target volume, planning the shape and direction of the beams, and accurate treatment delivery.

Proton therapy uses the spread out Bragg peak, which has a sharp lateral penumbra and no exit dose (Figures 1 and 2). This results in tight conformity to the tumour with minimal dose to the surrounding normal tissues. The integral dose, which is the total dose to normal tissues, is lowest with proton therapy. This is an

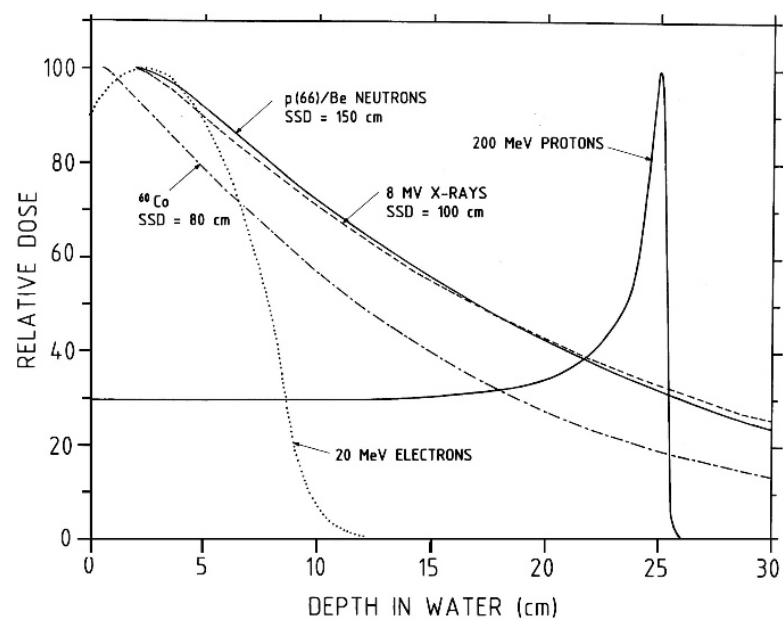

Figure 1 Depth dose curves for different radiation beams. Courtesy of Professor Dan Jones, iThemba LABS, Faure, Cape Town.

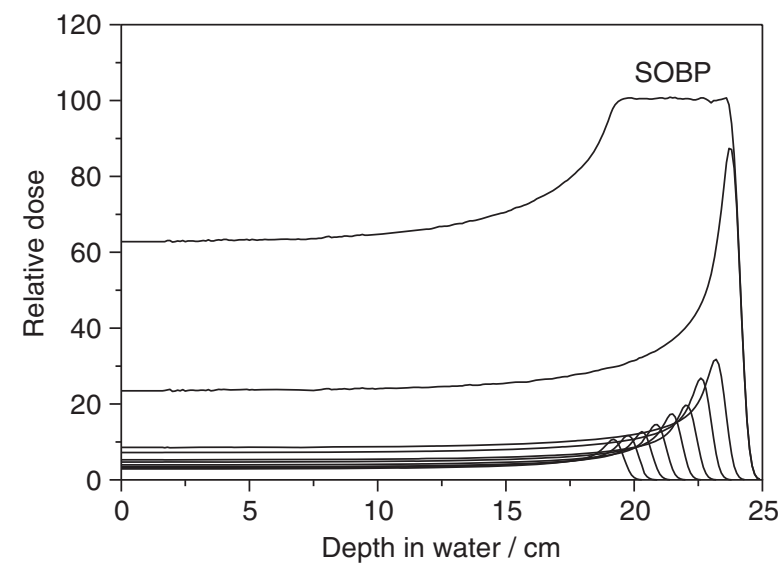

Figure 2 Spread out Bragg peak (SOBP) of a proton beam. Courtesy of Professor Dan Jones, iThemba LABS, Faure, Cape Town.

important consideration when treating children, to minimise the risk of second malignancies.

Stereotactic radiation may be delivered with a $\gamma$-knife (multiple Co-60 sources in a helmet), stereotactic linac (multiple arcs of beams), and cyberknife (a more mobile linac with small beams). All of the above are much more expensive than conventional RT, and the integral dose is greater than with proton therapy.

Treatment is usually delivered in multiple small fractions over a period of weeks. This increases tumour damage by allowing time for reoxygenation and reassortment of cells in the cell cycle making them more sensitive to RT. It also spares normal tissues by allowing time for sublethal damage to be repaired in between fractions. ${ }^{1}$ Conversely, stereotactic RT or proton therapy is delivered in one or a few large fractions, but to small 
discrete volumes, thus minimising the volume of surrounding normal tissue irradiated.

\section{Brachytherapy}

Brachytherapy is the placing of radioactive sources close to or into a tumour. Localised RT for uveal melanoma and retinoblastoma (RB) was initiated by Moore et $a l^{2,3}$ using radon seeds, Subsequently, Stallard ${ }^{4}$ developed radioactive applicators using radium-226. These were later superseded by Co-60 plaques. ${ }^{5}$ Lommatsch was the first to use Ru-106 plaques ${ }^{6}$ and Sealy et $a l^{7}$ was the first to use I-125 to treat ophthalmic tumours. Table 1 shows the characteristics of the various isotopes used, including whether $\beta$ or $\gamma$ emitters, the half-life (time taken to decay to half the activity), energy, half value layer in tissue ( $\mathrm{mm}$ of tissue required to reduce the energy to half), useful range in tissue, sclera to apex dose, and the amount of lead $(\mathrm{Pb})$ required to block the radiation by $95 \%$. Brachytherapy can be delivered by means of plaques, applicators, and interstitial implants. Brachytherapy is usually delivered at a low-dose rate between 0.4 and 1 Gray (Gy)/h, which simulates multiple small fractions.

\section{Dosimetry}

The dose prescribed usually refers to the energy absorbed per unit mass of tissue at a specified point; for example, the apex of the tumour with a plaque, the isodose encompassing the tumour with an implant, and the intersection of the beams with EBRT.

One Gy in Systéme International (SI) units indicates the absorption of 1 joule of energy by 1 kilogram of tissue and is equivalent to $100 \mathrm{cGy}$ or 100 rads.

Equal doses of different types of radiation do not produce equal biological effects.

Relative biological effectiveness (RBE) is used to compare different forms of radiation.

For example, the RBE of protons is 1.1, whereas that of neutrons and carbon ions is 3 .

\section{RT techniques for different sites}

\section{Conjunctiva}

Bulbar conjunctiva The most common malignant tumours of the bulbar conjunctiva are squamous cell carcinoma and malignant melanoma (Figure 3). The standard treatment for these tumours is excision together with adjunctive therapy consisting of cryotherapy, chemotherapy, or RT. RT is usually delayed until the conjunctiva has healed.

RT can be administered with a hand-held Sr-90 applicator delivering $60 \mathrm{~Gy}$ to the surface in four fractions once a week or $50 \mathrm{~Gy}$ in five daily fractions. Such treatment yields excellent rates of local control for squamous cell carcinoma, with minimal morbidity, provided that the plaque is sufficiently large to encompass the entire tumour bed (Figure 4). ${ }^{8}$ Tumours that are larger than the available applicator, or those that penetrate the sclera, are best treated with a custom-made I-125 plaque giving $60 \mathrm{~Gy}$ at $2-3 \mathrm{~mm}$ (Figure 5). The dose given for conjunctival melanoma after excision is $100 \mathrm{~Gy}$ in 4 weekly fractions of $25 \mathrm{~Gy}$. These bulbar tumours can also be treated with a Ru-106 plaque, which is applied either immediately after excision, delivering a dose of $130 \mathrm{~Gy}$ at $2 \mathrm{~mm}$ (Sauerwein, personal communication) or when the conjunctiva has healed with a dose of $100 \mathrm{~Gy}$ at $1-2 \mathrm{~mm} .^{9}$

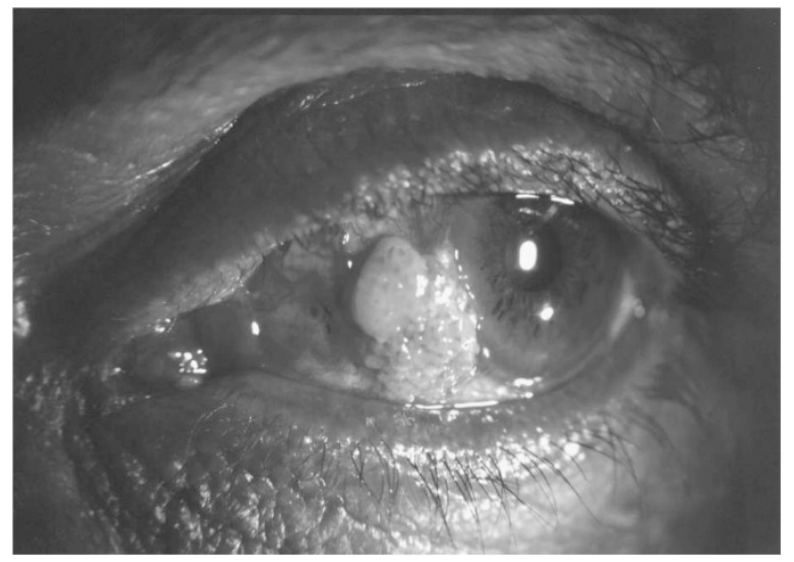

Figure 3 Squamous cell carcinoma of the conjunctiva.

Table 1 Properties of radioisotopes

\begin{tabular}{|c|c|c|c|c|c|c|}
\hline & $S r-90$ & $R u-106$ & $P d-103$ & $I-125$ & $I r-192$ & Co-60 \\
\hline Emission & $\beta$ & $\beta$ & $\gamma$ & $x+\gamma$ & $\gamma$ & $\gamma$ \\
\hline Half-life & 28.8 years & 374 days & 17 days & 60 days & 74 days & 5.26 years \\
\hline Energy $(\mathrm{MeV})$ & 2.27 & 3.54 & 0.021 & 0.027 & 0.38 & 1.25 \\
\hline HVL in tissue (mm) & 1.5 & 2.4 & 11 & 20 & & 116 \\
\hline Useful range $\mathrm{mm}$ & 2 & $5-6$ & & 13 & & \\
\hline Sclera:apex dose & & $5-10 \times$ & $3.5 \times$ & $3 \times$ & & \\
\hline $\mathrm{Mm} \mathrm{Pb}$ to reduce dose by $95 \%$ & & $1(\mathrm{Ag})$ & 0.06 & 0.25 & 15 & 60 \\
\hline
\end{tabular}

Abbreviations: Co, cobalt; HVL, half value layer; I, iodine; Ir, iridium; Pb, lead; Pd, palladium; Ru, ruthenium; Sr, strontium.

HVL tissue mm: depth at which radiation is reduced by half. 


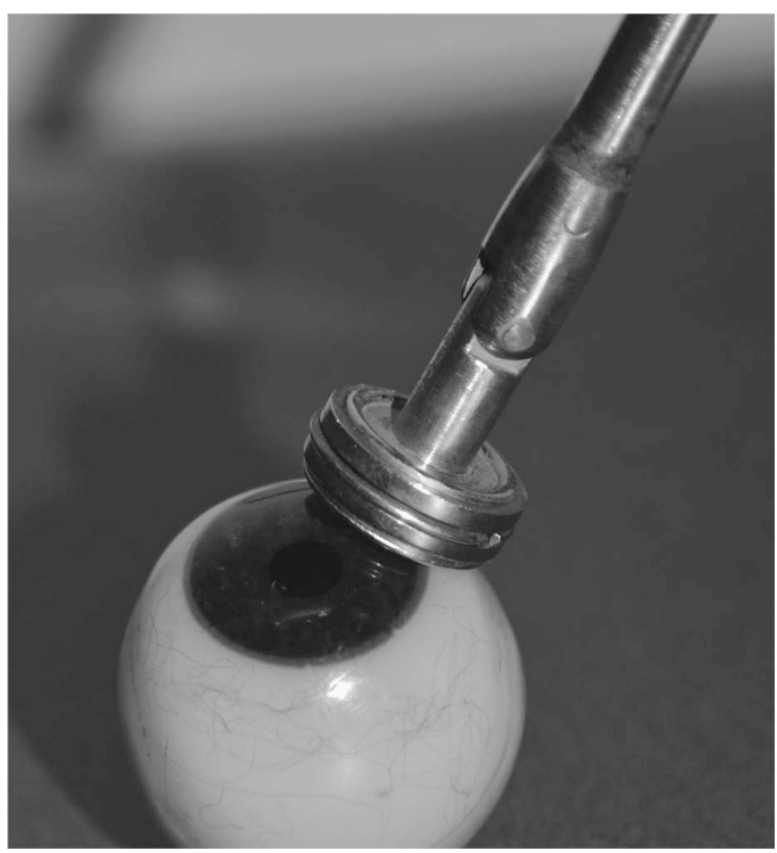

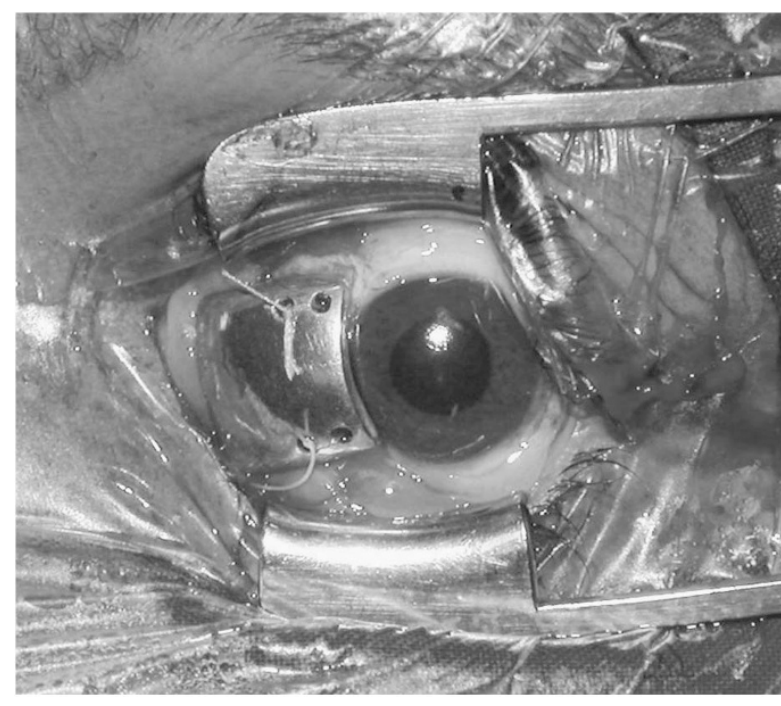

Figure 5 I-125 conjunctival plaque.

Figure 4 Sr-90 plaque.

\section{ELECTRON FIELDS}

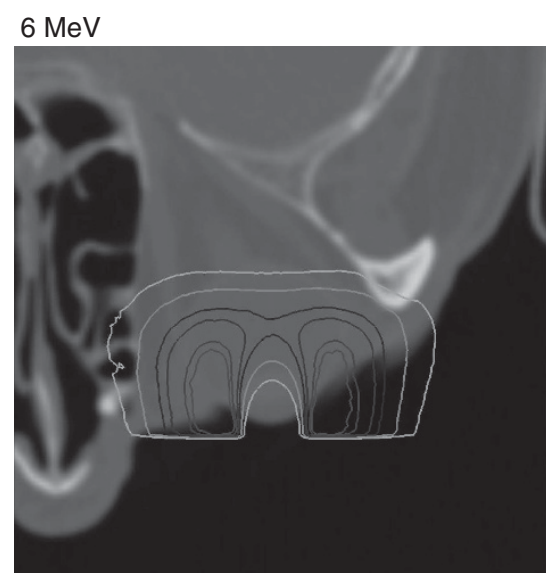

$9 \mathrm{MeV}$

Isodose lines: $100 \%, 95 \%, 80 \%, 70 \%, 50 \%, 30 \%$

Figure 6 Electron isodose curve showing central shielding. Reprinted with permission from Elsevier. ${ }^{10}$

Palpebral conjunctiva and fornix Mucosal-associated lymphoid tissue lymphoma is radiosensitive but requires treatment to the entire conjunctiva. This is achieved by EBRT with an anterior electron beam together with a central corneal/lens block (Figure 6) and bolus to compensate for the dose to the skin surface. ${ }^{10}$ A relatively low dose of 25-30 Gy in 2-2.5 Gy per fraction gives excellent local control. Complications, mainly cataract and to a lesser extent dry eye, do occur, but are less common and severe if the dose does not exceed 2 Gy per fraction. ${ }^{11,12}$ Despite achieving local control, the disease may be disseminated in
$10 \%$ of patients at diagnosis and in a further $10 \%$ subsequently.

Malignant melanoma and squamous cell carcinoma require a higher dose of radiation. This can be achieved with proton therapy, which can be shaped and compensated to treat the whole conjunctiva while minimising the dose to the rest of the eye. ${ }^{13}$ A dose of $32 \mathrm{~Gy}$ (RBE) in six fractions is given followed by a boost to the tumour bed of $14 \mathrm{~Gy}$ (RBE) in two fractions. The local control rate was $70 \%(14 / 20)$ in previously treated patients with malignant melanoma, with 13 (65\%) maintaining good vision but most developing a dry eye. ${ }^{14,15}$ 


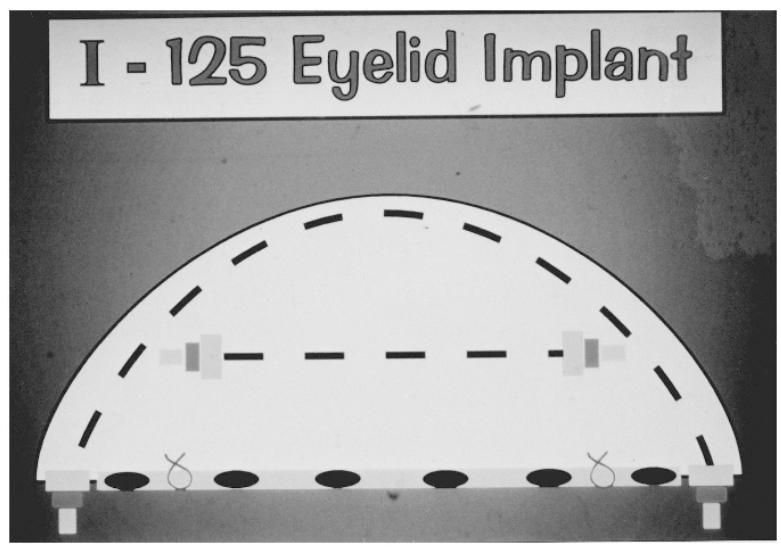

Figure 7 Diagram of implant to eyelid including palpebral conjunctiva. Reprinted with permission from Elsevier. ${ }^{16}$

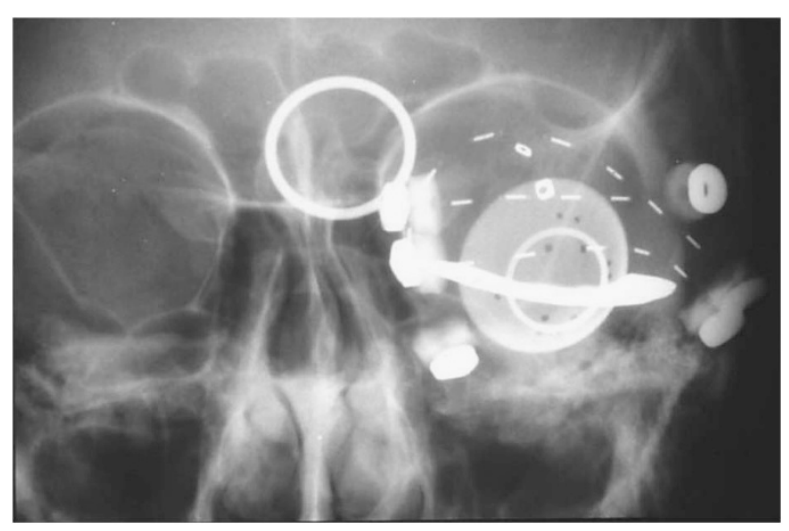

Figure 8 X-ray of eyelid implant showing metal shield, which protects the cornea and lens. Reprinted with permission from Elsevier. ${ }^{16}$

An alternative approach is brachytherapy delivered by implanting plastic tubes containing I-125 seeds into the eyelid. A stainless steel perilimbal shield attached to the extraocular muscles protects the cornea and the lens (Figures 7 and 8). A dose of 55-60 Gy over 5 days gave excellent local control in 13 of 14 patients with retention of good vision in 7 patients but with a dry eye in 5 patients. ${ }^{16}$

\section{Intraocular tumours}

Retinoblastoma Small localised RBs (ie, group A and B eyes) can be treated with transpupillary thermotherapy (TTT) or cryotherapy with or without chemotherapy. Discrete tumours that are $>4 \mathrm{~mm}$, group $\mathrm{C}$ eyes with localised vitreous seeds or tumours that have failed cryotherapy or TTT can be treated with an I-125 or Ru106 plaque. The usual dose with I- 125 is 40 Gy delivered in 4-5 days to the apex of the tumour with excellent local control rates of around $90 \% .{ }^{17}$ An anterior inactive extension to custom-built plaques facilitates the

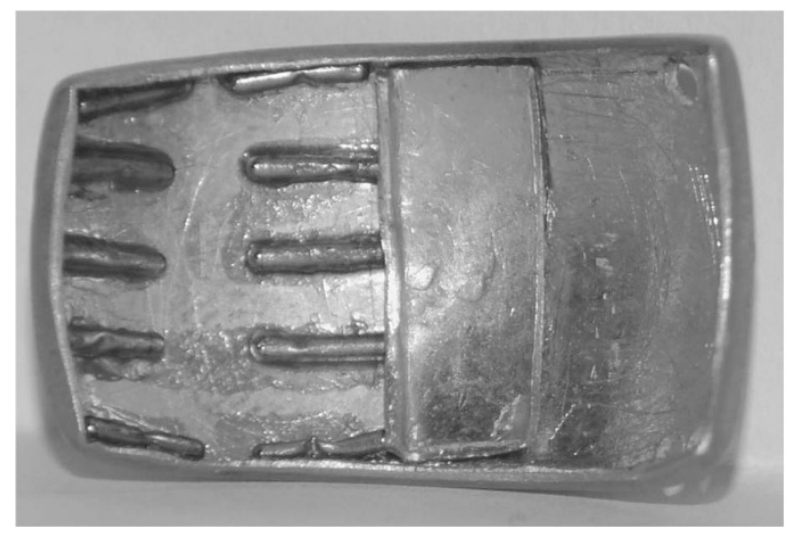

Figure 9 I-125 plaque showing anterior unloaded extension.

positioning for tumours in the posterior pole of the eye (Figure 9). ${ }^{18}$ The dose used with Ru-106 plaques in Essen is $80 \mathrm{~Gy}$ to the apex, although most tumours responded with a dose of at least $50 \mathrm{~Gy} .{ }^{19}$ There is no comparative dosimetry of I-125 and Ru-106 and there appears to be a disparity in the doses used. They cannot simply be transposed from one isotope to the other.

RT to the whole eye may be necessary for some group $\mathrm{C}$ eyes and most group $\mathrm{D}$ eyes if other methods fail (ie, systemic chemotherapy + TTT, intraarterial, or intravitreal chemotherapy).

This can be done with EBRT, using the Schipper ${ }^{20}$ technique to spare the lens and anterior eye. With this technique, suction contact lenses are placed on both eyes of the anaesthetised child and attached by rods to the extension of the D-shaped collimator of the linear accelerator so that the anterior edge of the beam, along the central beam axis, falls just posterior to the lens. A dose of 40 Gy in 1.8-2 Gy fractions is given. ${ }^{21}$ In Essen, there were recurrences at this dose and therefore $50 \mathrm{~Gy}$ is used.22 Alternatively, proton therapy can be administered with a single beam either encompassing the tumour or irradiating the whole posterior globe. The dose to the bony orbit is minimised by using an anterior oblique field and rotating the eye according to the tumour location. ${ }^{23}$ Another approach is an I-125 applicator, 'claws', developed by Sealy. It consists of four 'claws' loaded with I-125 seeds that are placed between each of the extraocular muscles and attached anteriorly to a pericorneal ring, which is itself attached to the four extraocular muscles (Figures 10 and 11). A dose of 40 Gy is given to the centre of the eye over 4 days. This has shown excellent results with local control and retention of vision in $85 \%$ of 13 group A-C eyes and a local control rate of $58 \%$ in 38 group D eyes with eye retention in $39 \% .{ }^{24,25}$ The design of the 'claws' applicator ensures considerable protection of the bony orbit. This results in good long-term cosmesis and there is no recorded incidence of second non-ocular malignancy. 


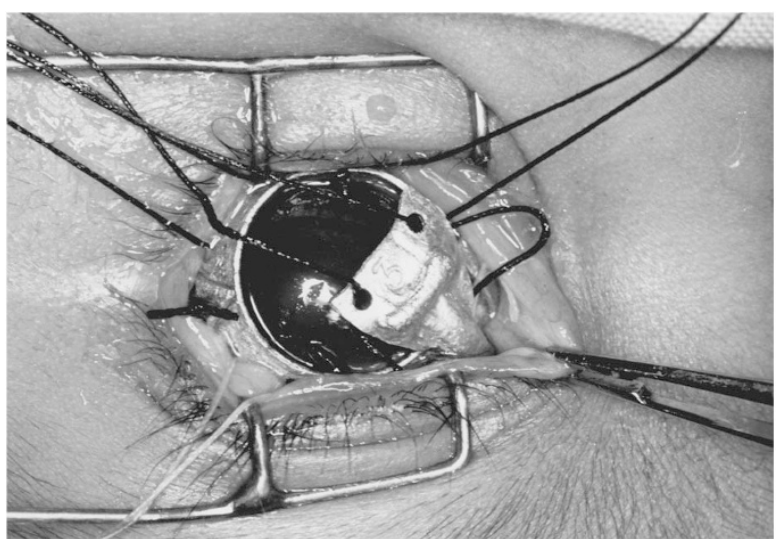

Figure 10 Insertion of one of the 'claws' of an I-125 applicator between the extraocular muscles and to be attached to the pericorneal ring, which is itself attached to the extraocular muscles. Reprinted with permission from Elsevier. ${ }^{24}$

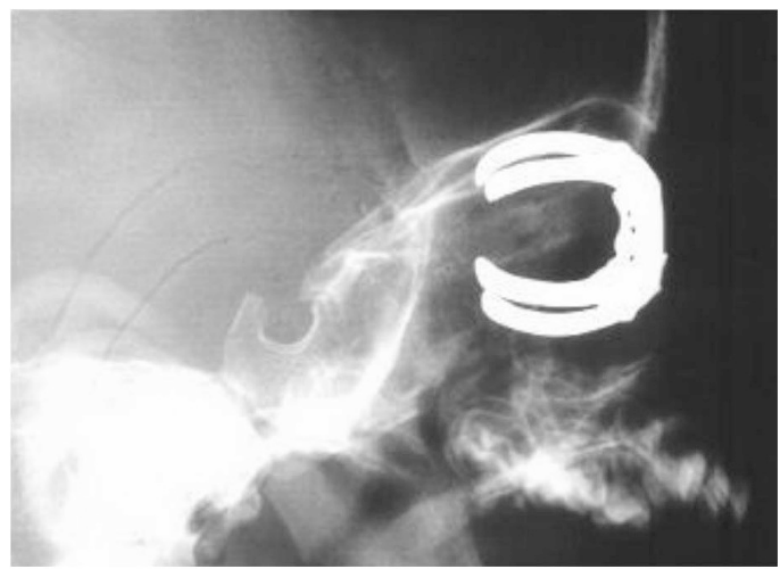

Figure 11 X-ray of 'claws' applicator. Reprinted with permission from Elsevier. ${ }^{24}$

Orbital RT is indicated in patients who are at risk for a local recurrence (ie, stage I, intrascleral and stage 2, microscopic extrascleral disease or optic nerve resection margin involvement). Such RT is preferably administered with brachytherapy so as to reduce the radiation dose to the bony orbit. Six plastic tubes are prepared, each with I- 125 seeds and a longitudinally sectioned hypodermic needle to shield them from the bony orbit. The tubes are implanted through the eyelids around the bony orbit to reach the apex of the orbit together with a seventh centrally placed unshielded train of seeds. A Pb disc with seeds glued to its posterior surface is secured under the eyelids (Figure 12). A dose of $40 \mathrm{~Gy}$ in 4 days is given with excellent local control of $100 \%$. Good cosmesis is achieved provided attention is paid to the ocular prosthesis. ${ }^{26}$ If a prosthetic implant is in situ, the central train can be omitted and the dose in the remaining trains adjusted accordingly. ${ }^{27}$ The implant can also be used if

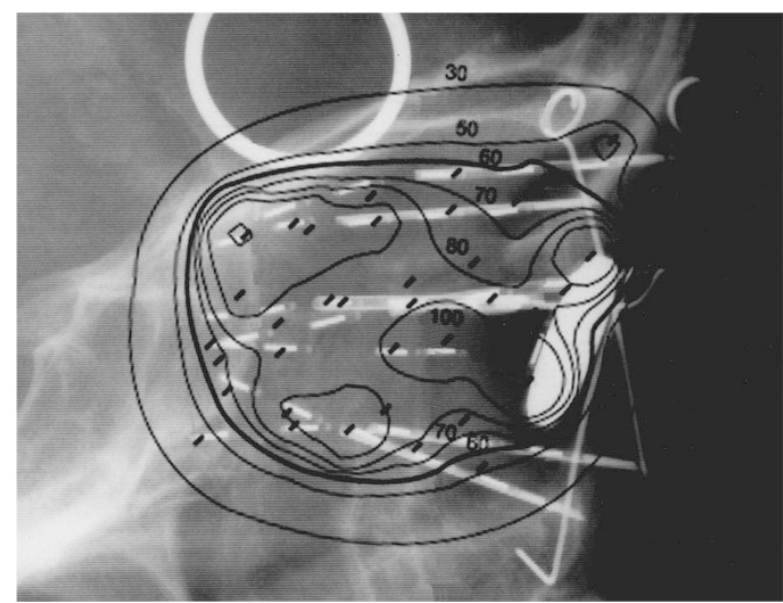

Figure 12 Lateral X-ray of an orbital implant with superimposed isodose lines. The bold $50 \mathrm{cGy} / \mathrm{h}$ covers the implant back to the apex of the orbit. Reprinted with permission from Elsevier. ${ }^{26}$

there is macroscopic orbital disease (stage III), provided that tumour does not extend to the apex or erode the bone. In such cases, EBRT should be given either with a wedge pair of fields with Co-60 or X-rays, or with a single-electron field delivering a dose of $40 \mathrm{~Gy}$ in $2 \mathrm{~Gy}$ fractions. Systemic chemotherapy is also necessary.

Uveal melanoma Uveal melanoma can be treated with plaque, proton therapy, or stereotactic RT. Plaque RT can be administered with Ru-106, I-125, or palladium 103 (Pd-103) plaques. Because of $\beta$ emission Ru-106 plaques are less penetrating and therefore should be reserved for tumours $<6 \mathrm{~mm}$ in height (Figure 13). I-125 and Pd-103 are both low-dose $\gamma$ emitters whose rays can be shielded completely behind the plaque and reduced laterally by the edges of the plaque. The energy of Pd-103 is $21 \mathrm{keV}$ compared with $27-35 \mathrm{keV}$ of I-125, which would reduce the dose of radiation to other structures in the eye.

However, the short half-life of only 17 days is a disadvantage because it limits the repeated use of the seeds. I- 125 plaques can treat tumours up to $10-13 \mathrm{~mm}$ but obviously the rate of complications increases with the height of the tumour. Ru-106 plaques are bought ready-made in a variety of 16 different sizes and shapes. I-125 plaques can be custom built to any shape or size, usually with a 2-mm margin around the tumour. Using a computer program and a variety of seed strengths, a constant dose and dose rate can be given to the apex of the tumour whatever the height. Both Ru-106 and I-125 plaques can be notched for tumours adjacent to the optic nerve or shaped to treat round or over the limbus for tumours of the ciliary body or iris (Figure 14). ${ }^{28}$ Alternatively, the COMS circular plaques with five sizes and matching inner silastic moulds for easy placement of the seeds can be used; however, these cannot be placed 


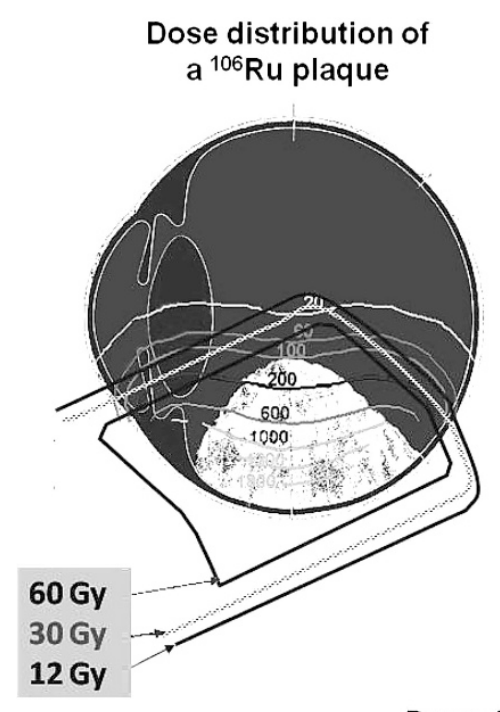

Dose distribution of a proton beam

Figure 13 Comparative dose distributions of proton therapy, Ru-106, and I-125 plaques. Tumour thickness $=8 \mathrm{~mm}$. Courtesy of Dr Dirk Fluehs, Universistatsklinikum, Essen.

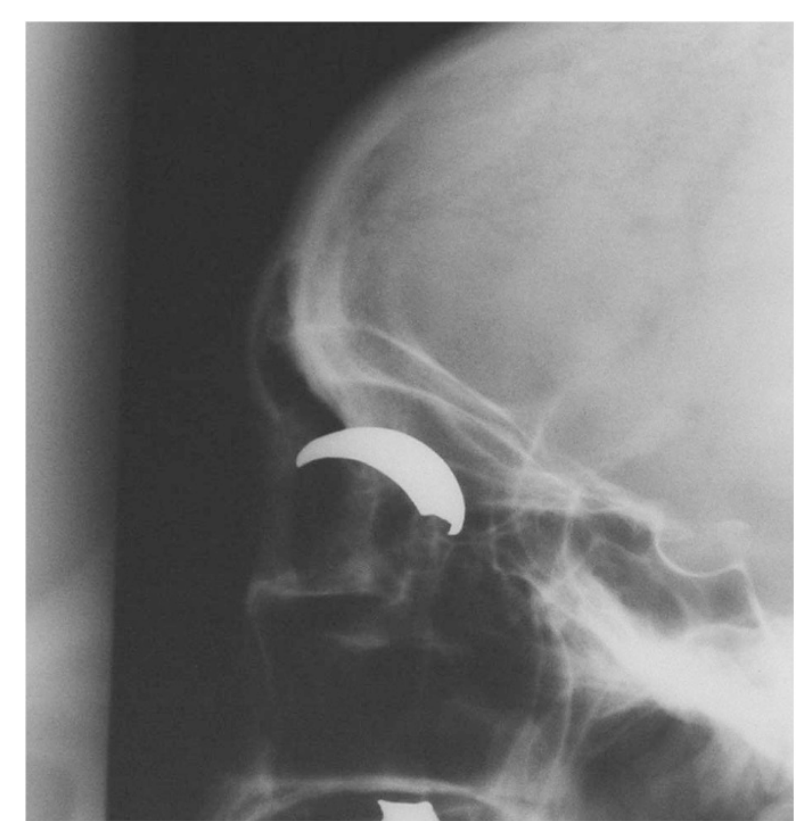

Figure 14 X-ray of notched I-125 plaque for a malignant melanoma adjacent to the optic nerve.

close to the optic nerve. ${ }^{29}$ The same plaque has been used with Pd-103..$^{30}$ The dose given by various centres varies considerably. Doses for Ru-106 vary from 60 to 130 Gy with the majority giving 80-100 Gy. Doses for I-125 vary from 60 to $100 \mathrm{~Gy}$ with the majority giving 80-90 Gy. Char et al $^{31}$ found no difference in local control whether 70 or 80 Gy was given with an I-125 plaque.
Complications are present even at lower doses. The dose rate should be between 0.4 and $1 \mathrm{~Gy} / \mathrm{h}$. Ideally, treatment should take less than a week so that the plaque/seeds can be reused in a regular weekly operating schedule. The dose for Pd-103 was $81 \mathrm{~Gy}$. The local control rate with plaque therapy is between 90 and $95 \% .^{32-36}$

Plaques can also be used after local resection, transsleral, or transretinal, in which case only the tumour bed would be treated to $2-3 \mathrm{~mm}$ by $50-60$ Gy I- 125 or 100 Gy Ru-106. ${ }^{37}$

Proton therapy has been used for uveal melanomas since 1975. It involves the attachment of clips to the sclera at known distances from the tumour for localisation; immobilisation of the patient with a cast and bite-block; and meticulous planning from three-dimensional modelling using all available clinical, radiological, and ultrasonographical data. From this data the beam profile, depth and width of the SOBP, and the ideal eye position can be calculated. The position of the eye is fixed according to the location of the tumour by fixing the contralateral eye on a specified point. Doses of $60 \mathrm{~Gy}$ in four fractions ${ }^{38,39}$ and $70 \mathrm{~Gy}$ in five fractions ${ }^{40}$ have been used. This latter dose has been reduced to $50 \mathrm{~Gy}$ also in five fractions, but without any significant difference in either local control or complications. ${ }^{39}$ Local control with protons is about $95 \%$ in most series. ${ }^{38-40}$

Stereotactic RT with a $\gamma$ knife started with 55 Gy in one fraction, reducing slowly over several years of experience to $31 \mathrm{~Gy}$. With a stereotactic linear accelerator, 60-70 Gy in five fractions was given but this was then reduced to $50 \mathrm{~Gy}{ }^{41}$ 
Choroidal haemangioma Choroidal haemangiomas have been treated with a Pd-103 or I-125 plaque, 30 Gy; proton therapy 18-20 Gy in 4 fractions; and photon therapy 20-25 Gy. ${ }^{42-45}$ These doses are sufficient to ensure local control of the lesion and the secondary retinal detachment. It is important that treatment is instituted before visual loss is severe and prolonged.

Choroidal metastases The treatment of choroidal metastases depends on the primary site and the extent of metastases.

If the primary tumour usually responds to hormone therapy or chemotherapy, then this would be the first option. If the primary tumour is not hormone- or chemosensitive or the choroidal metastases are unresponsive to systemic treatment, they can be treated with RT; either with a plaque for a solitary metastasis with a reasonable life expectancy or EBRT. The dose of EBRT depends on life expectancy (eg, 20 Gy in 5 fractions for lung origin with a short life expectancy, 30-40 Gy in 3 Gy fractions for metastases from a breast carcinoma with a longer life expectancy.

\section{Conclusions}

RT alone, or combined with other modalities, is important in the treatment of ocular tumours. The challenge to control the tumour with minimal morbidity to the eye continues as more sophisticated techniques become available. Cooperation between all specialities involved is of paramount importance.

\section{Conflict of interest}

The authors declare no conflict of interest.

\section{References}

1 Hall E. Radiobiology for the Radiologist. 5th edn. Lippincott, Williams \& Wilkins: Philadelphia, 2000.

2 Moore RF. Choroidal sarcoma treated by the intraocular insertion of radon seeds. Br J Ophthalmol 1930; 14: 145-156.

3 Moore RF, Stallard HB, Milner JG. Retinal gliomata treated by radon seeds. Br J Ophthalmol 1931; 15: 673-696.

4 Stallard HB. Radiotherapy of intraocular neoplasms. Br J Ophthalmol 1948; 32: 619-639.

5 Stallard HB. Radiotherapy for malignant melanoma of the choroid. Br J Ophthalmol 1966; 50: 147-155.

6 Lommatsch PK, Volmer R. Ein neuer Weg zur konservativen Therapie intraokularerTumoren mit Betestrahlen (106Ru/106Rh) unter Erhaltung der Sehfahigkeit. Klin Monatsbl Augenheilkd 1966; 148: 682-699.

7 Sealy R, le Roux PLM, Rapley F, Hering E, Shackleton D, Sevel D. Treatment of ophthalmic tumours with low-energy sources. Br J Radiol 1976; 49: 551-554.

8 Lecuona K, Stannard C, Hart G, Myer L, Wetter J. The treatment of squamous carcinoma of the conjunctiva with beta irradiation. Presented at the International Society of Ocular Oncology (ISOO) meeting. Cambridge: England. 8-12 September 2009.

9 Damato B, Coupland SE. An audit of conjunctival melanoma treatment in Liverpool. Eye 2009; 23: 801-809.

10 Brualla L, Zaragoza FJ, Sempau J, Wittig A, Sauerwein W. Electron irradiation of conjunctival lymphoma. Monte Carlo simulation of the minute dose distribution and technique optimization. Int J Radiat Oncol Biol Phys 2012; 83: 1330-1337.

11 Goda JS, Le LW, Lapperriere NJ, Millar BA, Payne D, Gospodarowicz MK et al. Localised orbital mucosaassociated lymphoma managed with primary radiation therapy: efficacy and toxicity. Int J Radiat Oncol Biol Phys 2011; 81: e659-e666.

12 Hata M, Omura M, Koike I, Tomita N, lijima Y, Tayama Y et al. Treatment effects and sequelae of radiation therapy for orbital mucosa-associated lymphoid tissue lymphoma. Int J Radiat Oncol Biol Phys 2011; 81: 1387-1393.

13 Chauvel P, Caujolle JP, Sauerwein W, Friedrichs W, Brassart $\mathrm{N}$, Herault J. Proton therapy as a possible salvage treatment for conjunctival melanomas. In: Frezzotti R, Balestrazzi E, Falco L (eds) Intraocular and Epibulbar Tumors. Monduzzi Editore: Bologna, 1994, pp 177-181.

14 Sauerwein W, Stannard CE. Auge und Orbita. In: Bamberg M, Molls M, Sack H (eds) Radioonkologie Band 2: Klinik, W. Zuckschwerdt Verlag München Wien: New York, 2009, pp 294-316.

15 Wuestemeyer H, Sauerwein W, Meller D, Chauvel P, Schueler A, Steuhl KP et al. Proton radiotherapy as an alternative to exenteration in the management of extended conjunctival melanoma. Graefes Arch Clin Exp Ophthalmol 2006; 244: 438-446.

16 Stannard CE, Sealy GRH, Hering ER, Pereira SB, Knowles R, Hill JC. Malignant melanoma of the eyelid and palpebral conjunctiva treated with I-125 brachytherapy. Ophthalmology 2000; 107: 951-958.

17 Shields CL, Shields JA, Cater J, Othmane I, Singh AD, Micaily B. Plaque therapy for retinoblastoma. Long term tumour control and treatment complications in 208 tumors. Ophthalmology 2001; 198: 2116-2121.

18 Stannard C, Sealy R, Shackleton D, Hill J, Korrubel J. The use of I-125 plaques in the treatment of retinoblastoma. Ophthalmic Paediatr Genet 1987; 8: 89-93.

19 Schueler AO, Fluhs D, Anastassiou G, Jurklies C, Neuhauser M, Schilling $\mathrm{H}$ et al. $\beta$-ray brachytherapy with $\mathrm{Ru}-106$ plaques for retinoblastoma. Int J Radiat Oncol Biol Phys 2006; 65: 1212-1221.

20 Schipper J. An accurate and simple method for megavoltage radiation therapy of retinoblastoma. Radiother Oncol 1983; 1: 31-41.

21 Toma NMG, Hungerford JL, Plowman PN, Kingston JE, Doughty D. External beam radiotherapy for retinoblastoma: II. Lens sparing technique. Brit J Ophthalmol 1995; 79: 112q-117q.

22 Messmer E, Sauerwein W, Heinrich T, Hopping W, Klueter-Reckmann D, Bornfeld $\mathrm{N}$ et al. New and recurrent tumor foci following local treatment as well as external beam radiation in eyes of patients with hereditary retinoblastoma. Graefe's Arch Clin Exp Ophthalmol 1990; 228: 426-431.

23 Krengli M, Hug EB, Adams JA, Smith AR, Tarbell NJ, Munzenrider JE. Proton radiation therapy for retinoblastoma: comparison of various intraocular tumour 
locations and beam arrangements. Int J Radiat Oncol Biol Phys 2005; 61: 583-593.

24 Stannard C, Sealy R, Hering E, Korrubel J, Hill J, Barron A et al. Localised whole eye radiotherapy for retinoblastoma using an I-125 applicator, 'Claws'. Int J Radiat Oncol Biol Phys 2001; 51: 399-409.

25 Stannard C, Hering E, Lecuona K, Maree G, Munro R, Davidson A. Localised whole eye therapy for retinoblastoma using an iodine-125 applicator, 'claws'. Presented at the International Congress of Ocular Oncology (ICOO). Siena, Italy. 25-30 June 2007.

26 Stannard C, Sealy R, Hering E, Hough J, Knowles R, Lecuona $\mathrm{K}$ et al. Postenucleation orbits in retinoblastoma: treatment with I-125 brachytherapy. Int J Radiat Oncol Biol Phys 2002; 54: 1446-1454.

27 Stannard C, Maree G, Munro R, Lecuona K, Sauerwein W. Iodine-125 orbital brachytherapy with a prosthetic implant in situ. Strahlenther Onkol 2011; 187: 322-327.

28 Shields CL, Naseripour M, Shields JA, Freire J, Cater J. Custom-designed plaque radiotherapy for non-resectable iris melanoma in 38 patients: tumour control and ocular complications. Am J Ophthalmol 2003; 85: 648-656.

29 The Collaborative Ocular Melanoma Study Group. Design and methods of a clinical trial for a rare condition: The Collaborative Ocular Melanoma Study. COMS report no. 3 Control Clin Trials 1993; 14: 362-373.

30 Finger PT, Berson A, Ng T, Szechter A. Palladium-103 plaque radiotherapy for choroidal melanoma: an 11 year study. Int I Radiat Oncol Biol Phys 2002; 54: 1438-1445.

31 Char DH, Castro JR, Quivey JM, Phillips TL, Irvine AR, Stone RD et al. I-125 brachytherapy versus helium ion irradiation. Ophthalmology 1989; 96: 1708-1715.

32 Packer S, Stoller S, Lesser ML, Mandel FS, Finger PT. Long term results of iodine-125 irradiation of uveal melanoma. Ophthalmology 1992; 99: 767-774.

33 Fontanesi J, Meyer D, Xu S, Tai D. Treatment of choroidal melanoma with I-125 plaque. Int J Radiat Oncol Biol Phys 1993; 26: 619-623.

34 Wilson M, Hungerford J. Comparison of episcleral plaque therapy and proton beam radiation therapy for the treatment of choroidal melanoma. J Ophthalmol 1999; 106: 1579.

35 Shields C, Naseripour M, Cater J, Shields JA, Demirci H, Youseff $\mathrm{A}$ et al. Plaque radiotherapy for large posterior uveal melanomas ( $\geqslant 8 \mathrm{~mm}$ thick) in 354 consecutive patients. Ophthalmology 2002; 109: 1838-1849.

36 Kivela T, Puusaari I, Damato B. Transscleral resection versus iodine brachytherapy for choroidal malignant melanoma 6 millimeters or more in thickness: a matched case-control study. Ophthalmology 2003; 110: 2235-2244.

37 Damato B. Adjunctive plaque radiotherapy after local resection of uveal melanoma. Front Radiat Ther Oncol 1997; 30: 123-132.

38 Egger E, Zografos L, Schalenbourg A, Beati D, Boehringer T, Chamot L. Eye retention after proton beam radiotherapy for uveal melanoma. Int J Radiat Oncol Biol Phys 2003; 55: 867-880.

39 Dendale R, Lumbroso-Le Rouic I, Noel G, Feuvret L, Levy C, Delacroix $\mathrm{S}$ et al. Proton beam radiotherapy for uveal melanoma; results of Curie Institute-Orsay Proton Therapy Centre (ICPO). Int J Radiat Oncol Biol Phys 2006; 65: 780-787.

40 Gragoudas E, Wenjun U, Goitein M, Lane AM, Munzenrider JE, Egan KE. Evidence-based estimates of outcome in patients irradiated for intraocular melanoma. Arch Ophthalmol 2002; 120: 1665-1671.

41 Dunavoelgyi R, Dieckmann K, Gleiss A, Sacu S, Kircher K, Georgopoulos $\mathrm{M}$ et al. Local tumour control, visual acuity and survival after hypofractionated stereotactic photon radiotherapy of choroidal melanoma in 212 patients treated between 1997 and 2007. Int J Radiat Oncol Biol Phys 2011; 81: 100-205.

42 Aizman A, Finger PT, Shabto U, Szechter A, Berson A. Palladium-103 (103Pd) plaque radiation therapy for circumscribed choroidal hemangioma with retinal detachment. Arch Ophthalmol 2004; 122: 1652-1656.

43 Zografos L, Egger E, Bercher L, Chamot L, Munkel G. Proton beam irradiation of choroidal hemangioma. Am J Ophthalmol 1998; 126: 261-268.

44 Levy-Gabriel C, Rouic LL, Plancher C, Dendale R, Delacroix S, Assetain B et al. Long-term results of low dose proton beam therapy for circumscribed choroidal hemangioma. Retina 2009; 29: 170-175.

45 Ritland JS, Eide N, Tausjo J. External beam irradiation therapy for choroidal haemangioma. Visual and anatomic results after a dose of 20-25 Gy. Acta Ophthalmol Scand 2001; 79: 184-186. 